\title{
Unidades de paisagem da Costa Branca, nordeste do Brasil
}

\section{Landscape units of the Costa Branca, northeast of Brazil}

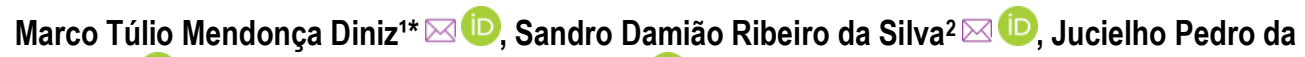 \\ Silva3凶(D), Diógenes Félix da Silva Costa ${ }^{1} \bowtie(D)$
}

1Departamento de Geografia, Centro de Ensino Superior do Seridó, Universidade Federal do Rio

Grande do Norte, Caicó, Rio Grande do Norte, Brasil

Recebido (Received): 08/07/2019

2 Doutorando no Programa de Pós-Graduação em Geografia, Centro de Ciências Humanas,

Letras e Artes, Universidade Federal do Rio Grande do Norte, Natal, Brasil

3Mestrando no Programa de Pós-Graduação em Geografia, Centro de Ensino Superior do Seridó,

Universidade Federal do Rio Grande do Norte, Caicó, Brasil

E-mails: sandrosilvausa@gmail.com (SDRS); jucyelho@hotmail.com (JPS);

dfscosta@ceres.ufrn.br (DFSC)

*E-mail para correspondência: tuliogeografia@gmail.com

Resumo: A Costa Branca é uma porção da Costa Semiárida Brasileira que se estende por $230 \mathrm{~km}$ entre os estados do Ceará e o Rio Grande do Norte. Partindo de tal área como o recorte empírico da pesquisa, o objetivo do trabalho foi mapear as unidades de paisagem de sua planície costeira. A área, predominantemente semiárida, é composta por nove unidades de paisagem, que foram mapeadas mediante os aspectos fisionômicos (geofácies) visualizados na escala de 1:50.000, além da realização da subdivisão da Costa Branca em seis subcompartimentos. Para tanto, foram utilizadas técnicas de geoprocessamento e sensoriamento remoto, por meio da vetorização de dados cartográficos em imagens de alta resolução, em conjunto com trabalhos de campo, propiciando o apontamento e discussão de potencialidades e fragilidades das unidades de paisagem. Em termos biogeográficos, o clima semiárido influencia na ocorrência, distribuição e formação peculiares da flora encontrada nos diferentes ambientes analisados. Mesmo sob condições de estresse hídrico anual, os ecossistemas aí encontrados ainda provêm uma série de serviços de grande importância para as comunidades tradicionais locais. Estes importantes aspectos devem ser levados em consideração para o gerenciamento costeiro deste trecho litorâneo específico do Brasil.

Palavras-chave: Costa Semiárida Brasileira; Costa do Sal; Geografia Costeira; Planície Costeira.

Abstract: The Costa Branca (White Coast) is a portion of the Brazilian Semi-Arid Coast that extends from $230 \mathrm{~km}$ between the states of Ceará and Rio Grande do Norte. In this empirical excerpt is the study area, whose objective of the research was elaborate maps of the landscape units of its coastal plain. The predominantly semi-arid area consists of nine landscape units, which were mapped using physiognomic aspects (geofacies) represented on a scale of 1:50,000, in addition to the subdivision of the Costa Branca into six sub-compartments. Therefore, geoprocessing and remote sensing techniques were used, by means of the cartographic data vectorization and high-resolution images, together with fieldwork, propitiating the pointing and discussion of potentialities and fragilities of the landscape units. In biogeographic terms, the semi-arid climate influences the occurrence, distribution and peculiar formation of the flora found in the different analyzed environments. Even under conditions of annual water stress, the ecosystems found there still provide a series of services of great importance to local traditional communities. These important aspects must be taken into account for the coastal management of this specific coastal stretch of Brazil.

Keywords: Brazilian Semi-arid Coast; Coast of Salt; Coastal Geography; Coastal Plain. 


\section{Introdução}

A Costa Branca foi recentemente delimitada por Diniz e Oliveira (2016) e se estende desde a Ponta Grossa, em Icapuí/CE, até o Cabo do Calcanhar, na Ponta do Farol de Touros/RN, com aproximadamente $230 \mathrm{~km}$ de extensão. A área tem as maiores taxas de salinidade de águas estuarinas do país (SILVA et al., 2009), com níveis comumente superiores à do oceano, com estuários que podem ser considerados invertidos, pois sua salinidade aumenta do oceano em direção ao continente (COSTA, 2010, COSTA et al., 2014a) (Figura 1).

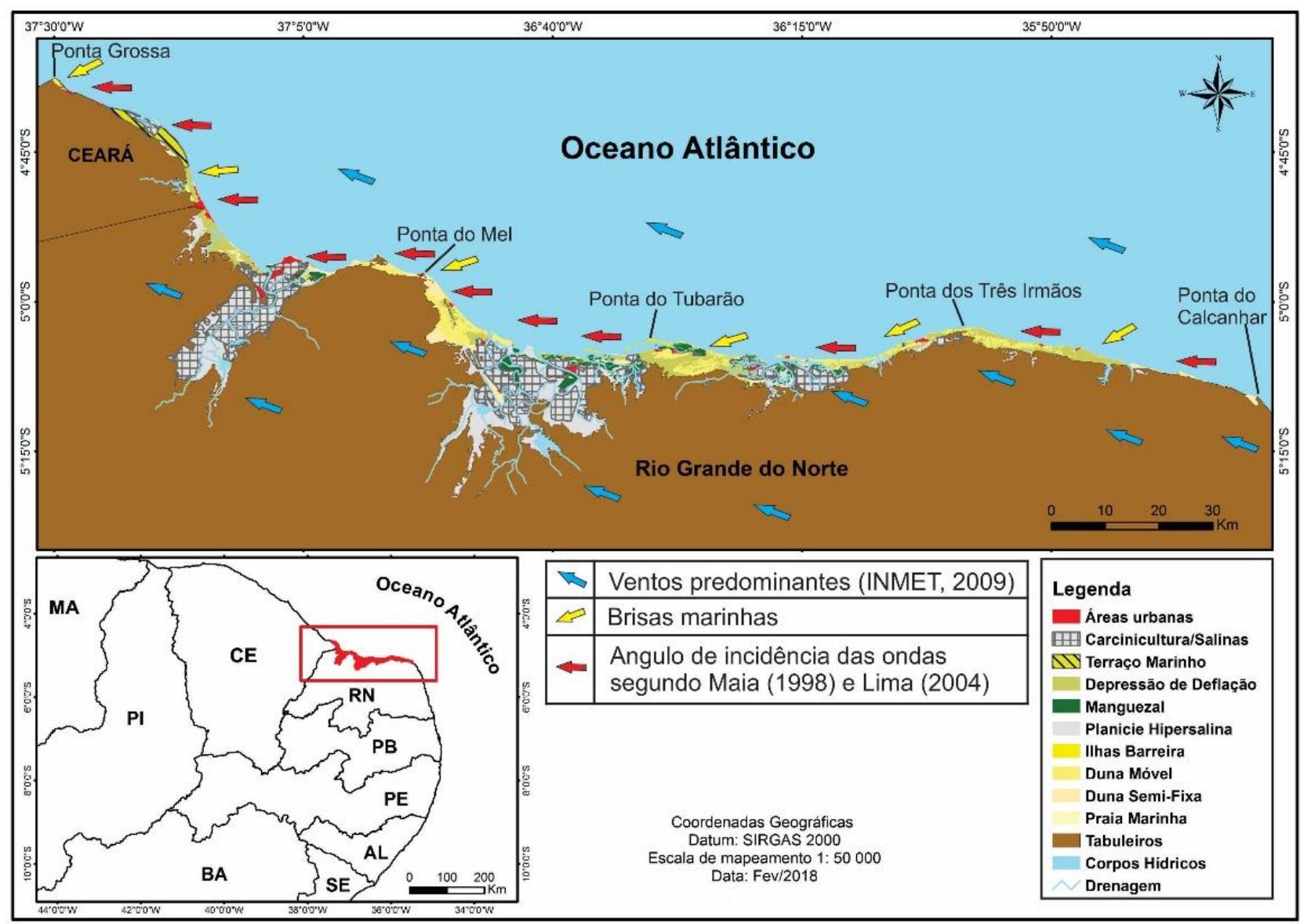

Figura 1: Localização da planície costeira da Costa Branca, destacando-se direção de ventos predominantes, brisas marinhas e ângulo de incidência de ondas neste trecho da Costa Semiárida Brasileira. Na figura, ainda podem ser vistos os setores da linha de costa, descritos mais a frente, após a apresentação das unidades de paisagem da referida planície.

De forma sintética, na Figura 1, é possível observar as áreas de dunas, que são mais largas nos trechos em que o litoral tem direção SE-NO - onde os ventos atuam de forma perpendicular, o que favorece à formação de dunas, já que nesta situação os sedimentos eólicos tendem a migrar do estirâncio para o interior - e menor onde a direção é E-O. Nestas últimas, o ângulo de incidência de ondas predominantes é paralelo à linha de costa, anulando o transporte longitudinal, o que é responsável pela acumulação sedimentar em forma de deltas na foz dos rios Apodi-Mossoró (RN) e do Piranhas-Açu (RN), assim como nos deltas de maré vazante em Galinhos/Guamaré (RN) e Icapuí (CE).

Este trecho do litoral brasileiro encontra-se sob influência do clima tropical de zona equatorial, quente e seco de subtipo semiárido (DINIZ; PEREIRA, 2015), apresentando uma distribuição das precipitações irregular e concentrada entre o verão e o outono (fevereiro a maio), com uma longa e pronunciada estação seca $(\sim 8$ meses $)$, cuja pluviosidade média anual $\left(800 \mathrm{~mm} \cdot \mathrm{ano}^{-1}\right)$ é inferior à evapotranspiração potencial da região (> 2000 mm.ano ${ }^{-1}$ ) (DINIZ, 2013).

Considerando-se as especificidades geoambientais acima descritas, este artigo teve como objetivo delimitar e mapear as unidades de paisagem da planície costeira da Costa Branca, bem como apresentar a avaliação dos ecossistemas e dos atributos biogeográficos, assim como as principais atividades produtivas de sua planície costeira. 


\section{Materiais e métodos}

Foi realizado mapeamento das unidades de paisagem na escala das geofácies em 1:50.000, considerando as unidades taxonômicas dos domínios morfoclimáticos, regiões naturais e geocomplexos do estado do estado do Rio Grande do Norte (DINIZ; OLIVEIRA, 2018). Em termos conceituais, Bertrand (1972) e Bertrand e Bertrand (2007) definem geofácie como sendo um setor fisionomicamente homogêneo, onde se desenvolve uma mesma fase da evolução do geocomplexo. Além disso, em conjunto com o geocomplexo, a geofácie é o único táxon onde o potencial ecológico (combinação dos fatores geomorfológicos, climáticos e hidrológicos), a exploração biológica (conjunto dos seres vivos e solo) e a ação antrópica podem ser trabalhados com amplitude.

Todos os mapas e Processamentos Digitais de Imagens (PDI) foram confeccionados em sistema de coordenadas geográficas a partir do datum SIRGAS 2000 (Zonas 24S e 25S), utilizando-se o software ArcGIS (ESRI® - versão acadêmica/Licença ${ }^{\circ}$ : EVA901905151), versão 10.4. O principal procedimento utilizado foi o de vetorização de unidades de paisagem vistas em imagens de alta resolução espacial $(0,5 \mathrm{~m})$, extraídas da seção Basemap do ArcGIS. Estas imagens são oriundas do satélite WorldView 2, de 27 de abril de 2012, as quais tem acurácia posicional de 10,2 metros.

A interpretação visual destas imagens foi feita a partir da Inferência à Melhor Explicação (IME), a qual combina a prática inferencial com a explicativa (DINIZ; SILVA, 2018). Ademais, houve a relação entre a interpretação visual com os objetos, classificando, a partir de diferentes critérios, áreas homogêneas (PANIZZA; FONSECA, 2011), elencando os seguintes elementos: forma, tonalidade, localização, textura e estrutura do objeto na Paisagem, em consonância com as características de cada geofácie

No que concerne à delimitação das geofácies, foram identificadas as porções que são visíveis ao olho humano (setores fisionomicamente homogêneos na paisagem), tais como: dunas, áreas agricultáveis, praias marinhas, entre outros. Nesta etapa, foram utilizadas, como base de delimitação inicial, as unidades de paisagem já existentes em outros mapeamentos (DINIZ; OLIVEIRA, 2018). A vetorização foi complementada por trabalhos de campo, para verificação in situ das características locais de cada unidade mapeada.

Para a identificação e análise dos ecossistemas e dos atributos biogeográficos, foi realizada uma Avaliação Ecológica Rápida, direcionada para as espécies e tipos vegetacionais presentes em cada geofácie (SAYRE et al., 2003). A identificação das espécies botânicas se deu a partir do sistema APG II, com auxílio de bibliografia especializada (SOUZA; LORENZI, 2005). De maneira complementar, também foram realizadas consultas aos sistemas Trópicos® (https://www.tropicos.org/home.aspx?langid=66), o qual contém dados e amostras botânicas do Missouri Botanical Garden, assim como ao Flora do Brasil 2020 INCT Herbário Virtual da Flora e dos Fungos (http://reflora.jbrj.gov.br/reflora). Os exemplares botânicos foram arquivados no Acervo de Amostras Botânicas do Laboratório de Biogeografia (UFRN/CERES Campus de Caicó).

\section{Resultados e discussões}

\subsection{Interações atmosfera-terra-oceano na Costa Branca}

Conforme evidenciado por Diniz e Oliveira (2016), a geometria da linha de costa influencia de forma decisiva as interações atmosfera-terra-oceano. De modo que, se compreendida em termos de trecho do litoral do Nordeste, a Costa Branca é um trecho predominantemente côncavo, com tendência para uma menor taxa de precipitação anual (KOUSKY, 1980). A área tem as menores taxas médias de pluviosidade do litoral brasileiro, com números médios anuais pouco maiores do que $500 \mathrm{~mm}$ em Macau/RN e $700 \mathrm{~mm}$ em Mossoró/RN (INMET, 2009).

A geometria da costa determina também a direção predominante dos ventos, que, por sua vez, são responsáveis pela orientação dos transpasses de dunas por deriva eólica. Na Costa Branca, as mencionadas dunas são principalmente barcanas ou parabólicas, móveis ou semi-fixas, que ocupam a faixa de terra frontal ao mar. Na área, apesar de os ventos terem direção resultante entre leste e sudeste na maior parte do ano, a direção da resultante destes é oeste e/ou sudoeste a depender da posição da linha de costa. 
Entre São Bento do Norte/RN e Caiçara do Norte/RN, cidades conurbadas, a geometria da linha de costa tem direção aproximadamente ENE-OSO, com ventos sinóticos de E e SE. Estes ventos não são os principais responsáveis pela formação e pelo transpasse de dunas, já que este ocorre no sentido SO (Figura 2), quase que paralelo ao da costa, o que nos leva a concluir que as brisas marítimas de NE são as responsáveis pela direção do transpasse de dunas nesta área.

São frequentes os distúrbios causados às construções civis aproximadas dessas dunas, dada sua dinâmica migratória que altera a paisagem em constância diária (Figura 2). Ao longo da direção da costa, é possível visualizar as dunas móveis majoritariamente no sentido SE-NO. Os ventos que propiciam a formação dessas dunas sopram das direções NE e E, os quais constituem a brisa marinha. Os alísios de SE não são capazes de formar dunas, pois sopram do interior para o litoral. Associados à brisa terrestre, são responsáveis pelo abastecimento das praias por sedimentos dunares.

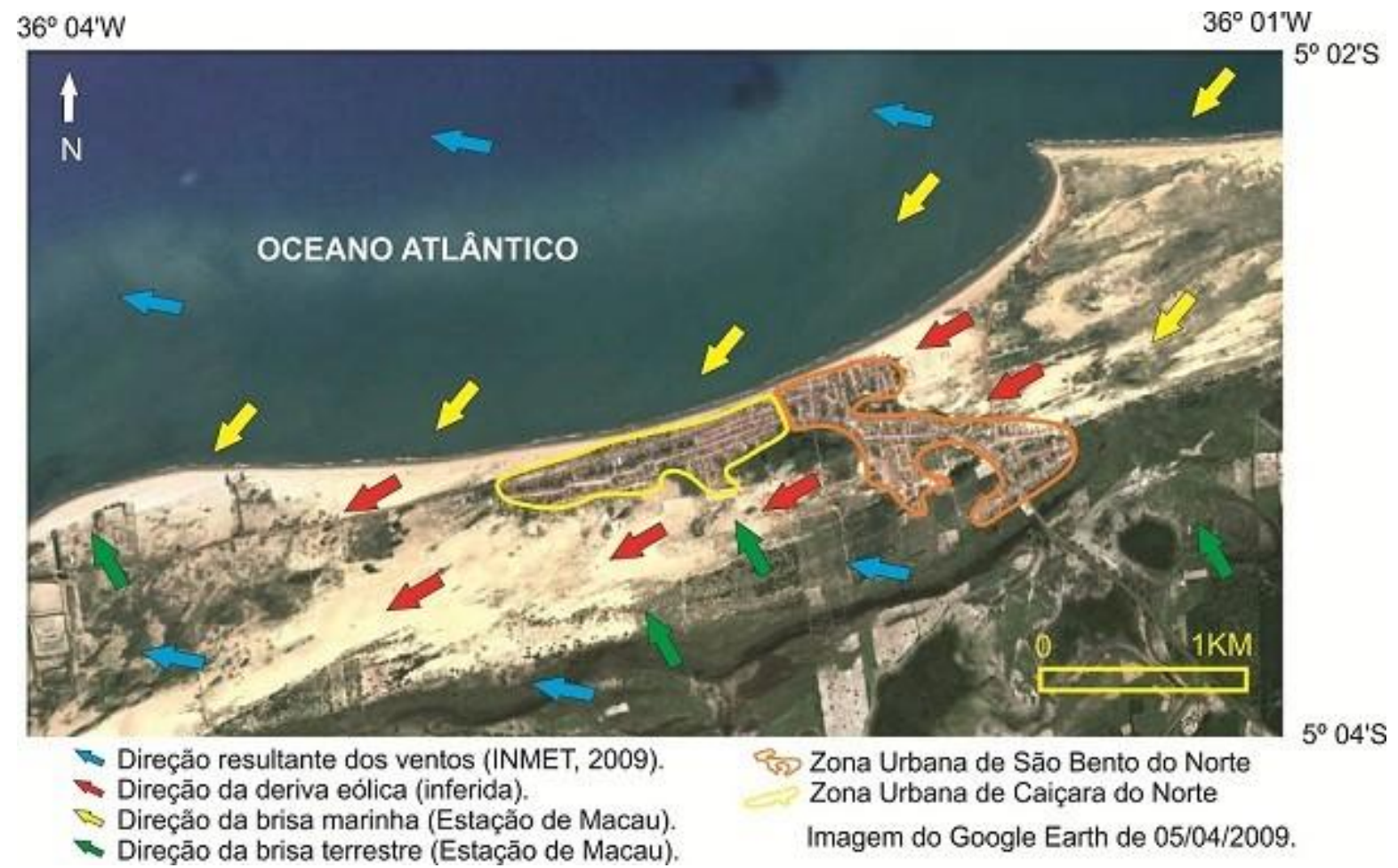

Figura 2: Direção resultante dos ventos, direção da deriva eólica, direção da brisa marítima (marinha) e direção da brisa terrestre entre São Bento do Norte/RN e Caiçara do Norte/RN. Fonte da imagem: Google Earth (Google.com (C)). Fonte dos dados INMET.

Os ventos Alísios de SE e a brisa terrestre de sul contribuem para a migração de sedimentos dunares de volta para a plataforma rasa entre os dois municípios que foram citados. A leste da área é possível perceber dunas parabólicas, já a oeste percebem-se montes sem cristas, nas quais a área urbana entre elas interrompeu o fluxo natural do transpasse de dunas.

Os processos acima descritos contribuem também, decisivamente, para a ocorrência de ilhas barreiras e restingas (spits, flechas de areia) e de alguns deltas de maré em pequenos estuários na área. A formação de ilhas barreiras e flechas de areia é um processo complexo que envolve os ventos Alísios de SE e E - que ocasionam migração de sedimentos do interior para o oceano -, associado às pequenas taxas de transporte longitudinal - as ondas na área provêm de leste, assim elas passam ao largo da linha de costa quando esta tem conformação E-O, de modo que o ângulo de incidência das ondas nessas áreas é próximo a zero (DINIZ; VASCONCELOS, 2017).

\subsection{Unidades de paisagem na Costa Branca}

Com base nos procedimentos metodológicos descritos anteriormente, foi possível definir a segmentação de nove geofácies da planície costeira da Costa Branca: Duna Móvel, Duna Semi-fixa, Depressão de Deflação, Ilha Barreira, Praia Marinha, Planície Hipersalina, Planícies Intertidais Colonizadas por Mangue, Terraços Marinhos e Unidades Antropizadas (carcinicultura/salinas e áreas urbanas). 
As Dunas móveis são corpos de areia formados a partir da acumulação de sedimentos, oriundos da praia. Tais sedimentos são removidos da face praial e depositados por meio dos agentes eólicos, além de sofrer influência das marés. Não possuem cobertura vegetal e, portanto, não são fixadas naturalmente, sendo sujeitas à migração sedimentar. Para a sua formação, fatores como a direção e a força dos ventos, a baixa declividade das praias e precipitações não regulares são necessários. Na Costa Branca, são encontradas dos tipos Barcana e outras com cristas Barcanóide (VITAL, 2006).

Estas feições estão presentes em toda a parte setentrional do Nordeste Brasileiro, desde a porção mais oriental (Touros) até o extremo oeste (Icapuí). As condições naturais da área favorecem a ocorrência de dunas móveis - principalmente a disponibilidade de material arenoso na plataforma rasa e nas falésias da Formação Barreiras, fortes ventos e o clima mais seco do litoral brasileiro - em detrimento de um pequeno número de Dunas Semi-fixas e de nenhuma ocorrência de duna fixa. Os processos pedogenéticos são inexistentes em grande escala, dificultando a fixação de vegetação, de modo que a morfogênese ganha sobressalto.

Por sua vez, as Dunas Semi-fixas estão em processo de transição entre as Dunas Móveis e as Dunas Fixas. Elas são antigas Dunas Móveis, no entanto, passaram por processos pedogenéticos, originando solos (neossolos quartzarênicos), e possuem a vegetação como agente fixador em determinadas partes da geofácie (Figura 3B). A migração de sedimentos existe, mas o processo migratório do corpo dunar é quase nulo. A vegetação que coloniza parte dessas dunas é arbustiva, formando um ecossistema de restinga, em virtude do Clima Semiárido (variando de 6 a 8 meses secos; Diniz e Pereira, 2015).

Na Costa Branca, o campo de Dunas Semi-fixas é consideravelmente menor que o de Dunas Móveis, aumentando em quantidade à medida que avança a leste, onde o clima é mais úmido na transição para o domínio da mata atlântica.

Os neossolos quartzarênicos compõem as Dunas Semi-fixas. Estes solos estão revestidos pela Savana Estépica Arborizada (IBGE, 2012), de caráter arbustivo (<3 metros). É importante mencionar que a irregularidade da distribuição da vegetação e do solo está interligada ao tempo de formação. Isto é, quanto mais desenvolvido o solo for e mais exuberante for a vegetação, mais antiga é aquela Duna Semi-fixa.

As Depressões de Deflação são comumente descritas na literatura como Planícies de Deflação. Podem ser definidas como "superfícies planas ou ligeiramente inclinadas, que se estendem desde o limite da maré alta até a base dos campos de dunas. Nestas superfícies, predomina a remoção de sedimentos pelos processos eólicos, com formação de feições residuais" (CEARÁ, 2006, p. 1). Todavia, considera-se que esta superfície está mais próxima do conceito de Depressão que do conceito de Planície, pois neste último os processos deposicionais superam os de erosão. Assim, tal superfície de deflação se aproxima do conceito de Guerra (1993, p. 125), no qual a Depressão é uma "ou porção do relevo situada abaixo do nível do mar, ou abaixo do nível das regiões que lhe estão próximas. [...] Depressão é, por conseguinte, uma forma de relevo que se apresenta em posição altimétrica mais baixa que as porções contíguas". Nesta geofácie, a erosão é maior que a deposição, já que a remoção sedimentar é constante e origina a formação de novos campos dunares.

Na Costa Branca, as Depressões de Deflação estão intercaladas por campos de Dunas Móveis e Dunas Semi-fixas (Figura 3C), podendo ser observadas ao longo de todo o território em análise. Ao leste, elas se situam ao Sul dos campos de Dunas Móveis que migram rumo ao continente, enquanto que na parte ocidental da área de estudo, é possível notar que elas estão dispostas a oeste das Dunas Móveis, como resultado da mudança gradual da direção dos ventos.

Naturalmente, as características são um misto daquelas descritas nas geofácies Duna Móvel e Duna Semifixa. Os ventos originários de $\mathrm{NE}$ e $\mathrm{E}$ são os responsáveis pela migração contínua de sedimentos nesta geofácie, o que dificulta a formação de solos, uma vez que existem apenas simples acumulações de sedimentos, limitando-se, no máximo, a um Neossolo Quartzarênico de Horizontes A-C.

A ausência de vegetação arbustiva é uma característica marcante, uma vez que a transitoriedade da recarga de sedimentos é a principal peculiaridade desta geofácie, onde ocorrem herbáceas das famílias amaranthaceae, bataceae, cyperaceae e poaceae em pequenos trechos.

Diferentemente das demais feições, as Ilhas Barreiras são formadas de maneira paralela à costa. Consistem numa faixa arenosa de tamanho variado, formadas pela ação constante da deriva litorânea, sempre trazendo, em seu escopo, as mudanças graduais relacionas ao nível do mar, podendo indicar, por exemplo, antigas linhas de costa. É desconectada do continente por feições ambientais úmidas (IBGE, 2009).

As Ilhas Barreiras (Figura 3F) presentes na área são oriundas de deposições naturalmente efetuadas ao longo do Quaternário, assim como os campos de Dunas, pontais arenosos, deltas de maré, etc. São extremamente susceptíveis aos processos erosionais, hidrodinâmicos e eólicos. Ocorrem nos trechos em que a costa tem conformação E-O, onde as ondas provenientes de E tem ângulo de incidência mínimo (DINIZ; 
VASCONCELOS, 2017), conforme já descrito. Exatamente neste trecho, são encontradas outras feições de restingas como esporões arenosos, como no caso do município de Galinhos (RN).

A evolução do sistema ilhas barreiras-esporões é cíclica, podendo um evoluir para o outro e vice-versa desde uma escala decadal até milhares de anos. Faz-se necessário enfatizar que não há uma geofácie denominado "esporão arenoso", pois os supracitados esporões foram encaixados na geofácie Duna Móvel, uma vez que estão diretamente conectados às terras continentais. Como já mencionado, as Ilhas Barreiras são de constituição recente, com sedimentos retrabalhados ao longo do holoceno. O relevo plano das Ilhas é visto sobre uma superfície predominantemente arenosa. A vegetação não se faz presente como agente fixador na área.

Em termos fitogeográficos, em função do substrato sedimentar arenoso de origem marinha nestes três ambientes (Duna Semi-fixa, Depressão de Deflação e Ilha Barreira), tem-se a ocorrência de uma comunidade vegetal psamófila (restinga fitogeográfica) de formação aberta, com apenas alguns indivíduos de porte arbóreo. Dentre estes, destacam-se as palmeiras das espécies carnaúba (Copernicia prunifera (Miller) H. E. Moore - PALMAE/ARECACEAE) e o coqueiro (Cocos nucifera L./PALMAE/ARECACEA). Também são encontrados indivíduos arbóreos de Anacardium occidentale L./ANACARDIACEAE (cajueiro), Commiphora leptophloeos (Mart.) J.B. Gillett./BURSERACEAE (imburana), Vitex montevidensis Cham./LAMIACEAE (azeitona de praia), Sideroxylon obtusifolium [Humb. ex Roem. \& Schult.] T.D. Penn/SAPOTACEAE (quixabeira) e a exótica Prosopis juliflora (Sw) DC/FABACEAE/MIMOSOIDEAE (algaroba).

Nestas unidades, também é bastante frequente a presença dos seguintes arbustos: Croton campestris A. St.-Hil/EUPHORBIACEAE (velame), Jatropha mollissima (Pohl) Baill./EUPHORBIACEAE (pinhão branco) e Cnidoscolus urens(L.)Arthur/EUPHORBIACEAE (urtiga). Quanto ao estrato herbáceo, verificase a predominância das seguintes espécies: Tapirira guianensis Aubl./ANACARDIACEAE, Elephantopus hirtiflorus DC/ASTERACEAE, Tournefortispp./BORAGINACEAE, Cuphea flava

Spreng./LYTHRACEAE, Sida spp./MALVACEAE, Paspalum spp./POACEAE e Borreria verticillata (L.) G. Mey/RUBIACEAE. Neste estrato, as espécies das famílias Convolvulaceae (Ipomoea spp., Ipomoea cairica (L.) Sweet, I. $\quad$ pes-caprae (L.) R.Br.), Cyperaceae (Abildgaardia sp., $\quad$ Cyperus hermaphroditus, C. ligulares, Fimbristylis sp.) e Fabaceae/Mimosoideae (Abarema sp., Centrosema brasilianum (L.) Benth., Clitoria sp., Mimosa camporum Benth.) apresentam o maior número de indivíduos.

Em trechos bem específicos, onde o teor de salinidade é mais elevando em relação ao entorno, verifica-se a ocupação destas áreas por uma comunidade de herbáceas halófilas, conhecidas popularmente como pirrixiu (e.g. Sesuvium portulacastrum (L.) L./AIZOACEAE, Blutaparon portulacoides (St-hil). Mears/AMARANTHACEAE, Salicornia spp./AMARANTHACEAE e Batis maritima L./BATACEAE).

Já as Praias Marinhas são depósitos de sedimentos (areia) acumulados, ao longo do tempo, por processos fluviais ou marinhos. Têm o tamanho variado de acordo com o tipo de maré que a influencia (GUERRA, 1993). É perceptível que, junto com os campos de Dunas Móveis, a paisagem é tomada, sobretudo, por feições arenosas planas (Figura 3A). Em quase toda a extensão das Praias Marinhas, é possível delimitar o seu término com o início das Dunas Móveis. A exceção ocorre na porção mais oriental da área, onde a Planície Costeira praticamente inexiste e os tabuleiros semiáridos (DINIZ; OLIVEIRA, 2018) chegam a esse limite.

A construção de cidades impede o contínuo fluxo natural de sedimentos, influenciando no balanço sedimentar e podendo provocar erosão. Como exemplos de cidades que artificializam o fluxo dos mencionados sedimentos, há os casos de Caiçara do Norte e São Bento do Norte (TABOSA, 2002).

As Planícies Hipersalinas são adjacentes aos Manguezais, onde as inundações pelas marés (de sizígia) são as principais responsáveis por aportes de água. Naturalmente, as condições naturais são baixas taxas de precipitação, altas temperaturas, elevada salinidade, elevadas taxas de radiação solar e de evaporação. A concentração de sais é, por vezes, mais alta que a capacidade de tolerância das espécies vegetais (PELLEGRINI, 2000). Na prática, trata-se da transição entre o Manguezal e a terra sempre emersa. Com isso, é possível perceber apenas uma vegetação rala em determinadas porções da paisagem (apicum) e superfícies sem vegetação alguma, em outras partes (salgado). Os solos (gleissolos sálicos) têm salinidade alta com mais de 150 partes por 1.000 (COSTA et al., 2014b). Estas duas feições da paisagem, apicum e salgado, foram unificadas aqui em uma só geofácie denominada Planície Hipersalina (Figura 3G).

Na área, as Planícies Hipersalinas estão dispostas em áreas estuarinas dos rios Apodi-Mossoró e PiranhasAçu e na Planície de Maré de Galinhos/Guamaré. De difícil delimitação, apicuns e salgados se entremeiam na paisagem após a vegetação de mangue, antecedendo, quase sempre, os tanques de carcinicultura ou das salinas. Estas áreas assumiram importância especial desde a colonização do Brasil, sendo ocupadas para construção 
de salinas solares, principalmente em virtude das características específicas desse tipo de solo, como alta salinidade e impermeabilidade (COSTA et al., 2013; DINIZ; VASCONCELOS, 2016).

Quando se verifica a ocorrência da planície hipersalina na transição entre o ambiente flúvio-marinho com ecossistema de manguezal, seguida de um gradiente de baixa elevação topográfica $(20-30 \mathrm{~cm})$ em substrato argiloso, têm-se a formação de uma zona ecotonal chamada de salgado, na qual verifica-se a ocorrência de uma comunidade vegetal halófila herbáceo-arbustiva.

Nesta comunidade, têm-se apenas uma população com poucos indivíduos arbustivos $(<2 \mathrm{~m})$ de Avicennia germinans (L.) L./ACANTHACEAE (mangue preto), única espécie que suporta elevados teores de salinidade, associada com um denso estrato herbáceo de pirrixiu/campo salino (IBGE, 2012) (e.g. Sesuvium portulacastrum (L.) L./AIZOACEAE, Blutaparon portulacoides (St-hil). Mears/AMARANTHACEAE, Salicornia spp./AMARANTHACEAE e Batis maritima L./BATACEAE). Em sequência a este ambiente, ainda em ambiente sedimentar argiloso, porém em cota topográfica acima do manguezal e do salgado, têm-se o ecossistema de apicum, no qual o elevado teor de salinidade superficiais derivado da inundação sazonal nas preamares (COSTA et al., 2014b) permite com que apenas se verifica a ocorrência das espécies herbáceas halófitas nas pequenas depressões nas quais a água fique acumulada por um período de tempo superior ao da dinâmica das marés.

Já as Planícies Intertidais Colonizadas por Mangue abrigam estes importantes ecossistemas costeiros que ocorrem nas zonas lamosas que sofrem influência das marés. Os manguezais possuem caráter arbustivoarbóreo e são distribuídos em estuários, lagoas, lagunas e deltas, sempre em áreas localizadas entre os trópicos (faixa intertropical). Predominam espécies vegetais típicas e trata-se de uma zona de elevada produtividade biológica (SCHAEFFER-NOVELLI; COELHO; TOGNELLA-DE-ROSA, 2004).

Situados unicamente nestes ambientes, estes ecossistemas e seus habitats associados (salgados e apicuns) encontram-se como os mais ameaçados pela elevação do nível médio do mar, uma vez que são ecologicamente vulneráveis a alterações mínimas no regime diário de inundação pelas marés (LOVELOCK et al., 2009). Verifica-se que uma mínima elevação $(<30 \mathrm{~cm})$ já limita a ocorrência das espécies vegetais (em função das suas características ecofisiológicas), comprometendo a estrutura ecológica de todo o ecossistema, assim como de seus habitats associados (TOMLINSON, 1986; LACERDA, 2017).

Os Manguezais ocorrem, principalmente, em três grandes regiões da Costa Branca: os estuários dos Rios Apodi-Mossoró e Piranhas-Açu, além da Planície de Maré de Guamaré e Galinhos. (Figura 3I). Estes ecossistemas fornecem uma ampla variedade de benefícios e serviços ambientais, incluindo a proteção das margens do estuário, as interações ecológicas com os ecossistemas marinho e fluvial, o fornecimento de recursos vegetais e animais para populações humanas, retenção de sedimentos, substâncias químicas e matéria orgânica (COSTA, 2017).

Em termos fitogeográficos, verifica-se em algumas desembocaduras de estuários que a transição entre a planície de infra-maré e a de intermaré é ocupada por uma densa população herbácea de Spartina alterniflora Loisel/POACEAE, seguida pelo manguezal arbustivo-arbóreo com as seguintes espécies: Rhizophora mangle L./RHIZOPHORACEAE (mangue vermelho ou mangue sapateiro), mais próximo a margem do estuário e a Avicennia schauerianna Stapf \& Leechm. Ex Moldenke (mangue língua de vaca ou siriúba), $A$. germinans (L.) L./ACANTHACEAE (mangue preto) e Laguncularia racemosa (L.) C. F. Gaertn/COMBRETACEAE (mangue branco ou amarelo), formando o bosque de interior.

Em um cenário de transição planície flúvio-marinha e planície praial ou planície de deflação, a zona de transição (ecótono) é ocupada por indivíduos arbustivos de A. germinans, L. racemosa e Conocarpus erectus L./COMBRETACEAE (mangue botão ou ratinho). De maneira associada a estas espécies, também se verifica a ocorrência de uma comunidade herbácea halófila (pirrixiu) aberta com as seguintes espécies: Sesuvium portulacastrum (L.) L./AIZOACEAE, Blutaparon portulacoides (St-hil). Mears/AMARANTHACEAE, Salicornia spp./AMARANTHACEAE e Batis maritima L./BATACEAE.

Por sua vez, os Terraços Marinhos são superfícies planas ou suavemente onduladas, contendo pequenos declives. Eles são originados a partir de processos de regressão marinha, sendo evidências de processos transgressivos (MEIRELES; RUBIO, 1999; SUGUIO, 2010). Assim, as características mineralógicas e sedimentares desta geofácie são capazes de evidenciar, com clareza, tais mudanças geológicas. Tais processos, por sua vez, são potencializados por súbitos levantamentos da costa, elevando, assim, a altitude de praias e plataformas de abrasão, sendo que estas últimas transformam-se, a partir de processos erosivos, nos Terraços (GUERRA, 1993). Desse modo, os Terraços possuem altitude mais elevada que o nível do mar.

$\mathrm{Na}$ Costa Branca, estas feições ocorrem apenas em Icapuí/CE (Figura 3D), sendo de duas gerações, uma plestocênica e os mais atuais do holoceno (MEIRELES, 2014), raramente ultrapassando os cinco metros de 
altitude e com neossolos quartzarênicos, com horizonte A pouco espesso. Estes solos são recobertos por uma vegetação rala, espaçada e de pequeno porte, que, obviamente, sobre influência do clima Semiárido.

Dentre as Unidades antropizadas, foram mapeadas áreas urbanas sobre a planície costeira. Inclusive, as sedes dos municípios de Icapuí (no Ceará), Tibau, Grossos, Areia Branca, Porto do Mangue, Macau, Guamaré, Galinhos, São Bento do Norte, Caiçara do Norte e São Miguel do Gostoso (no Rio Grande do Norte) estão assentadas sobre a planície costeira, algo incomum no Nordeste, uma vez que as sedes de quase todos os municípios costeiros estão assentadas nos tabuleiros e próximas aos rios, áreas mais estáveis e com disponibilidade de água doce em superfície. A convivência dos maiores núcleos urbanos com a instabilidade da planície costeira é uma característica peculiar desse trecho do litoral brasileiro (Figura 3H). Existem ainda as áreas de tanques de carcinicultura e salinas. Esta última atividade é, junto a pesca artesanal, a atividade fundante de toda a ocupação humana na Costa Branca.

Nesse trecho litorâneo, as salinas surgiram como uma das unidades mais presentes na paisagem encontrada nas margens dos estuários (COSTA et al., 2013), onde o seu funcionamento está expressamente relacionado com a variável espacial (COSTA, 2010). Portanto, as salinas representam um componente paisagístico predominante nessas regiões estuarinas, evidenciando-se a combinação de elementos que propiciam a auto-organização da paisagem ao longo da zona costeira.

Esse fluxo da água ao longo dos vários tanques cria um gradiente com características físico-químicas estáveis, principalmente com relação à salinidade. A organização espacial dos tanques nas salinas e suas diferentes profundidades, necessários para o processo de produção do sal, favorece o desenvolvimento de um alto grau de heterogeneidade espacial, com vários microambientes (COSTA, 2013).

Por sua vez, no Brasil e em todo o mundo, as atividades salineira e de carcinicultura são desenvolvidas também nestas zonas de planície de maré argilosas. A localização destas atividades em tais áreas se dá especificamente pelas características naturais que as mesmas propiciam (e.g. facilidade de captação de água nos canais de maré, substrato argiloso semipermeável, relevo plano). Estas características foram historicamente determinantes para a instalação do parque salineiro do Brasil (COSTA et al., 2013; DINIZ; VASCONCELOS, 2016), assim como para posterior chegada da atividade de criação de camarão em cativeiro. De fato, ao longo da linha de costa brasileira, apenas no litoral setentrional do estado do Rio Grande do Norte estão situadas as maiores empresas salineiras do país, principalmente nas margens dos seus estuários. Essas salinas são responsáveis por quase $97 \%$ do sal marinho produzido e exportado no país, influenciando diretamente nas economias locais e regionais através da geração de empregos e pagamento de impostos (COSTA et al., 2015).

Em termos de importância e valoração, tanto os ecossistemas de manguezal (principalmente) quanto as salinas prestam inúmeros serviços ecossistêmicos. No caso específico dos manguezais, evidencia-se a prestação de serviços primordiais para a sociedade, como os serviços de regulação do fluxo das marés, de provisão de alimentos, entre outros (JUNK et al., 2014; Costa, 2017). Por sua vez, estudos recentes identificaram a prestação de vários serviços ecossistêmicos prestados pelas salinas solares (COSTA et al., 2014a), desde a provisão de alimentos em seus tanques evaporadores até serviços culturais, como a prática de rituais religiosos afrodescendentes em seus taludes. COSTA et al. (2015) ainda ressaltam a importância estratégica da atividade salineira como de utilidade pública, em função da obrigatoriedade legal da adição do iodo ao sal marinho brasileiro, como medida nacional de combate aos casos de doenças como o hipertireoidismo e tireoidite de Hashimoto. 


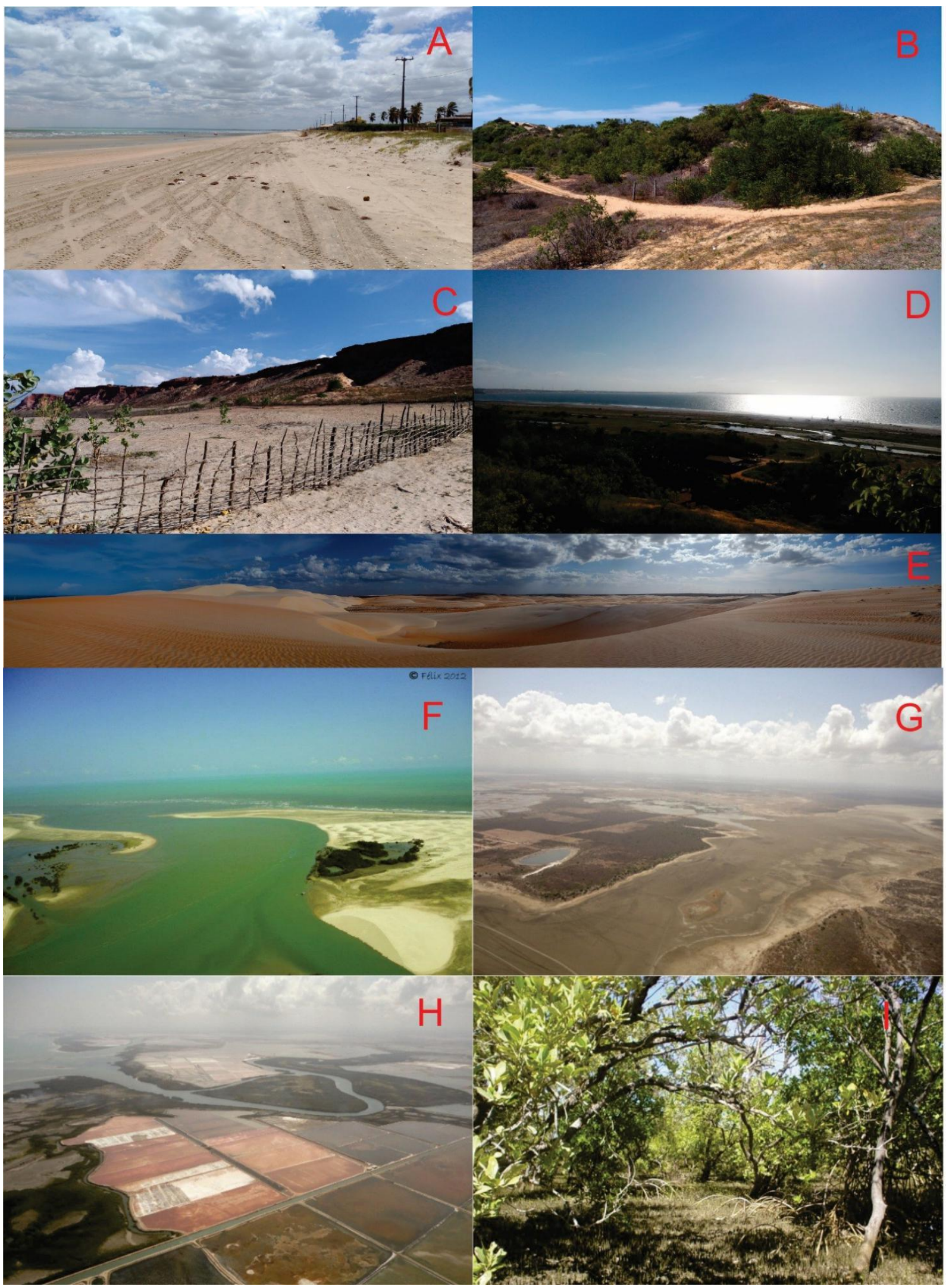

Figura 3: Mosaico fotográfico das unidades de paisagens na Costa Branca (A - Praia Marinha em área urbanizada de Tibau-RN; B - Dunas Semi-Fixas em Touros-RN; C - Depressão de Deflação em Areia Branca-RN em primeiro plano e com falésias inativas ao fundo; D - Terraços Marinhos ao fundo, vistos do alto de Duna Semi-fixa em Icapuí-CE; E - Dunas do Rosado de cores esbranquiçadas e rosadas em Porto do Mangue-RN; F - Dunas Móveis e Ilhas barreiras na foz do estuário do Rio das Conchas, um dos braços do delta do rio Piranhas-Açu, em Porto do Mangue-RN; G - Planície Hipersalina em Porto do Mangue-RN; H Zona estuarina com manguezais e tanques de salinas mecanizadas no Rio dos Cavalos, um dos braços do delta do rio Piranhas-Açu entre Porto do Mangue e Macau-RN; I - Ecossistema de manguezal no estuário do Rio Apodi-Mossoró em Grossos-RN. Fonte - Fotografias retiradas por Marco Túlio M. Diniz (UFRN/CERES/DGC) e Diógenes F.S. Costa (UFRN/CERES/DGC) 


\section{Os subcompartimentos da Costa Branca}

O Subcompartimento Icapuí-Tibau, inicia na Ponta Grossa em Icapuí/CE e vai até o início do estuário do rio Apodi-Mossoró/RN (Figura 4). A planície costeira de Icapuí é formada principalmente por uma série de cordões litorâneos pleistocênicos e principalmente holocênicos (MEIRELES, 2014), uma costa muito baixa e alagadiça. A leste, a linha de costa tem conformação ESE-OSO, onde é diminuto o transporte longitudinal, razão pela qual se formou um delta de maré vazante com diversos bancos de areia e pequenas ilhas colonizadas por manguezais. Este delta tem características estuarinas que formaram com contribuição de água doce freática.

O Subcompartimento Estuário do Rio Apodi-Mossoró compreende parte do território dos Municípios de Areia Branca, Grossos e Mossoró. Se tratava de uma área naturalmente ocupada por manguezais e planícies hipersalinas, a maior parte dessas últimas substituídas por tanques de carcinicultura e, principalmente, salinas (COSTA, 2010) (Figura 4). As características naturais conferem aos estuários dos rios Apodi-Mossoró e Piranhas-Açú e ao Delta de Maré de Galinhos/Guamaré o maior potencial para a produção de sal marinho do Brasil. A exploração de sal para o consumo humano na área é pré-colonial, mas se converteu em principal atividade econômica nos estuários desde o Século XIX (COSTA et al., 2013; DINIZ; VASCONCELOS, 2016).

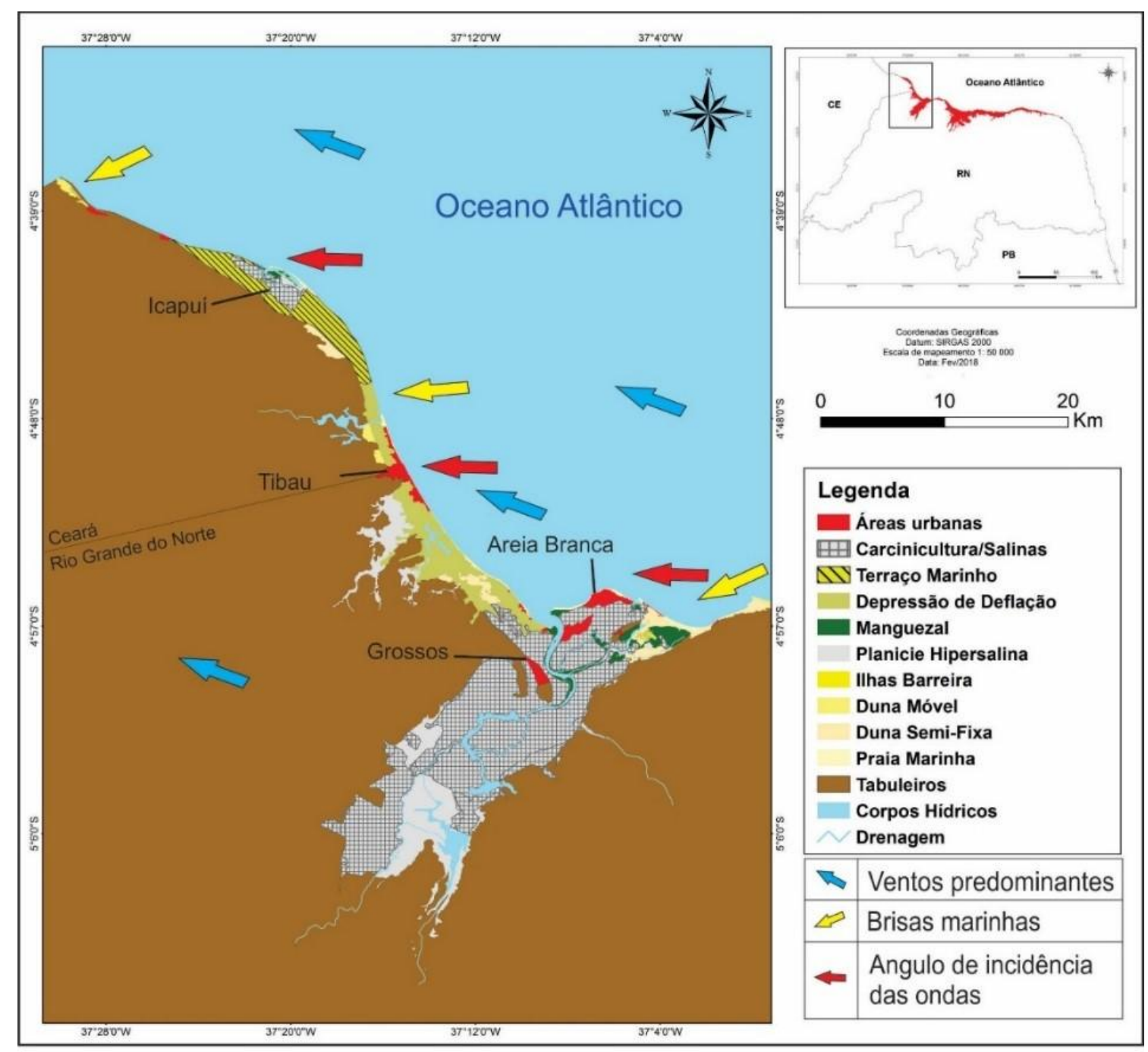

Figura 4: Direção resultante dos ventos, direção da deriva eólica, direção da brisa marítima (marinha) e direção da brisa terrestre na planície costeira dos subcompartimentos Icapuí/Tibau estuário do Rio ApodiMossoró/RN. Fonte dos dados INMET.

A área abriga manguezais e Planícies Hipersalinas, parte delas substituídas por salinas que produzem $100 \%$ do sal marinho do Ceará. Ao sul dos cordões, a costa tem conformação SSE-NNO, onde inexistem feições de acumulação de barreiras e se formam feições de Dunas Móveis e Depressões de Deflação eólica. 
Existe uma área urbana conurbada no limite dos estados RN-CE entre a cidade de Tibau e a comunidade da praia do Ceará que ocupam a planície costeira.

De acordo com os últimos dados divulgados pelo Departamento Nacional de Produção Mineral (DNPM, 2015) e por Costa et al. (2015), no ano base de 2014, a produção brasileira de sal foi de 7,5 milhões de toneladas (Mt), sendo a produção de sal marinho de $6 \mathrm{Mt}$, dos quais 5,7 Mt foram produzidos nos estuários do Açú, Mossoró e Galinhos/Guamaré, no Rio Grande do Norte (RN), o que equivale a cerca de $95 \%$ do total nacional. Deste percentual, apenas o delta de maré de Icapuí produziu outro 1,5\% do total nacional, totalizando em cerca de 96,5\% do total nacional da produção de sal marinho na Costa Branca.

O Subcompartimento Areia Branca-Porto do Mangue é um trecho a leste do estuário do rio ApodiMossoró, compreendendo os municípios de Areia Branca e Porto do Mangue. É um subcompartimento de costa mais elevada graças ao domo da Serra do Mel, uma elevação dômica com centro ao sul da área que foi capaz de levantar a costa e formar falésias no contato da Formação Barreiras com o Oceano (MAIA, 2012).

Predominam dunas, parte delas formadas sobre a Formação Barreiras e recebendo contribuição de sedimento avermelhado proveniente da erosão eólica das falésias. As dunas têm cor branca quando predomina sedimento de origem praial e rosada quando o sedimento tem no arenito Barreiras (que tem tom avermelhado) e nas praias, formando paisagens peculiares de dunas rosadas entremeadas por Depressões de Deflação como nas Dunas do Rosado (Figura 3E). A linha de costa varia bastante, pois há três pontas seguidas de enseada. As dunas são mais extensas nos trechos de costa SE-NO, principalmente a SE da Ponta do Mel e menos extensas nos trechos de costa ENE-OSO pelos motivos já mencionados.

O sub-compartimento Estuário do Rio Piranhas-Açú compreende parte dos municípios de Porto do Mangue e Macau, sendo o segundo maior delta da Costa Semiárida Brasileira (inferior apenas ao Delta do Parnaíba) com área estuarina de mais de 220 km² (DINIZ; VASCONCELOS, 2017).

O compartimento é cheio de feições de barreiras arenosas como flechas de areia e ilhas. O transporte longitudinal é praticamente nulo, pois a linha de costa tem conformação E-O. Neste compartimento, é possível identificar algumas características comuns à Costa Branca, como a restrita ocorrência de manguezais aos cursos d'água estuarina, presença de paisagens esbranquiçadas de salinas e planícies hipersalinas. Os manguezais são restritos aos canais fluviais. A área abriga alguns tanques de salinas de alguns quilômetros quadrados todos em cota $0 \mathrm{~m}$ de altitude.

O Subcompartimento Deltas de Maré de Diogo Lopes-Galinhos/Guamaré compreende parte dos municípios de Macau, Galinhos e Guamaré. É uma área rebaixada pela Falha de Afonso Bezerra. Ocorrem dois sistemas de delta de maré vazante, um em Diogo Lopes e outro entre Galinhos e Guamaré, separados um do outro e do delta do pelo campo de Dunas de Diogo Lopes que se originou de em trecho de costa com conformação OSO-ESE, onde o transpasse de dunas tem ocorrido na direção OSO como resultado da ação das brisas marinhas.

$\mathrm{Na}$ área das planícies de maré, a costa é E-O, com transporte longitudinal próximo de nulo e com várias feições de deposição de barreiras arenosas como flechas de areia, ilhas e bancos de areia. Em Diogo Lopes (município de Macau), predominam os manguezais. Já em Galinhos e Guamaré, grande parte deles foi substituído por salinas que ocuparão antigos manguezais e planícies hipersalinas. Atualmente ocorre criação de camarão também em áreas de planície hipersalina mais interiorana.

O Subcompartimento São Bento do Norte-Touros situa-se a leste do delta de Galinhos, ocupa a planície costeira dos municípios de Galinhos, São Bento do Norte, Caiçara do Norte, Pedra Grande, São Miguel do Gostoso e Touros, com limite leste no Cabo (Ponta) do Calcanhar ou Ponta do Farol de Touros.

O trecho tem duas direções predominantes uma ENE-OSO de Galinhos até a Ponta dos Três Irmãos, donde inflete para o outro ESE-ONO até a Ponta do Calcanhar. O primeiro trecho tem um campo de dunas mais estreito que migra no sentido OSO de forma paralela à costa, de modo que os sedimentos são carreados pelas brisas marinhas de NE e ENE. Como já dito, este campo de dunas é interrompido pela área urbana de São Bento do Norte e Caiçara do Norte e tem dunas de formato bastante complexo, dado que atuam na área alísios de ESE e brisa terrestre de Sul, além das brisas marinhas mencionadas (Figuras 2 e 6). Por sua vez, o segundo trecho tem cristas barcanóides mais pronunciadas, com transpasse com direção E, resultante da deflexão para E das brisas marinhas por parte dos ventos alísios de SE. 


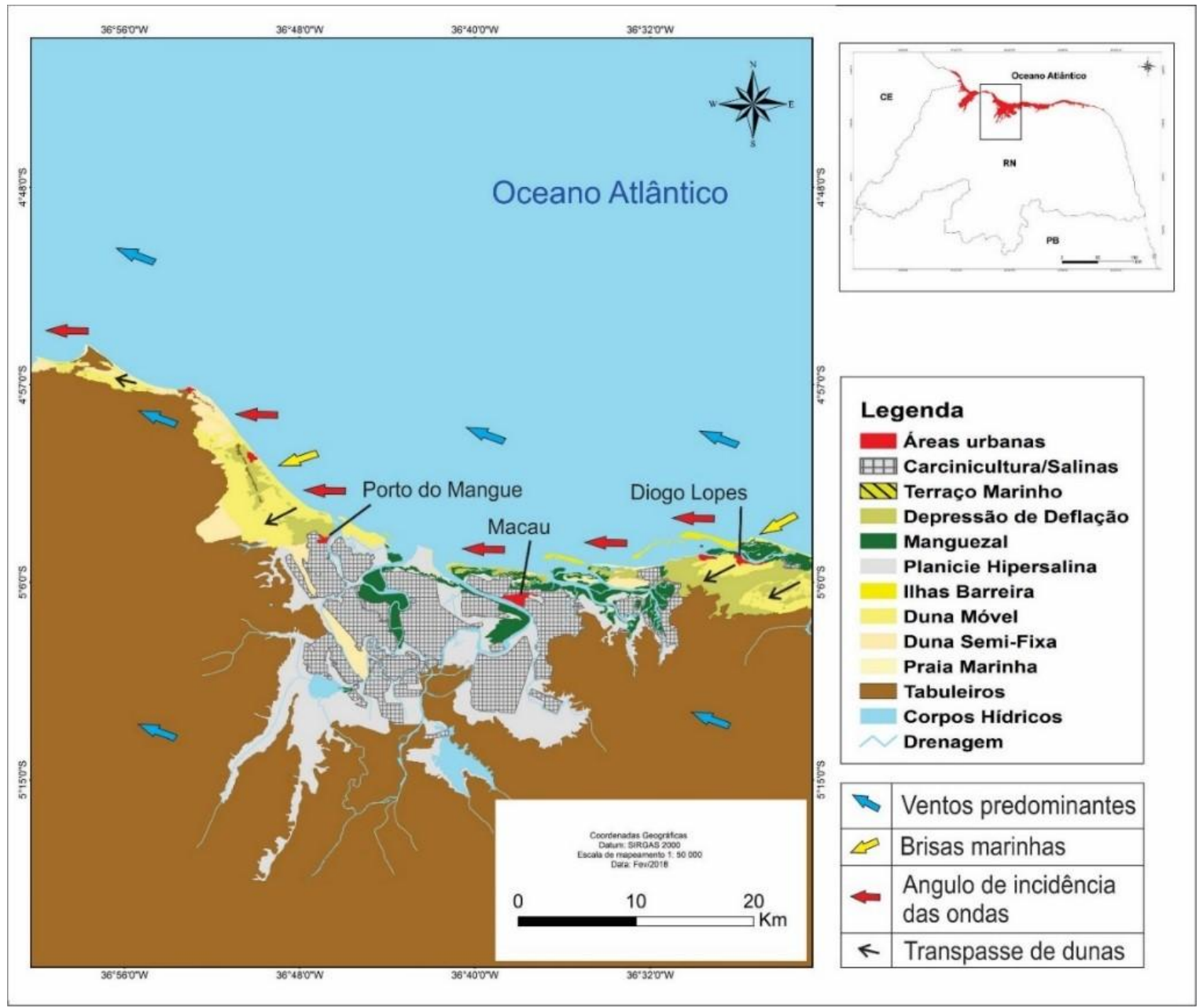

Figura 5: Direção resultante dos ventos, direção da deriva eólica, direção da brisa marítima (marinha) e direção da brisa terrestre na planície costeira dos subcompartimentos Areia Branca-Porto do Mangue; Estuário do rio Açú; e o delta de maré de Diogo Lopes. Fonte dos dados INMET.

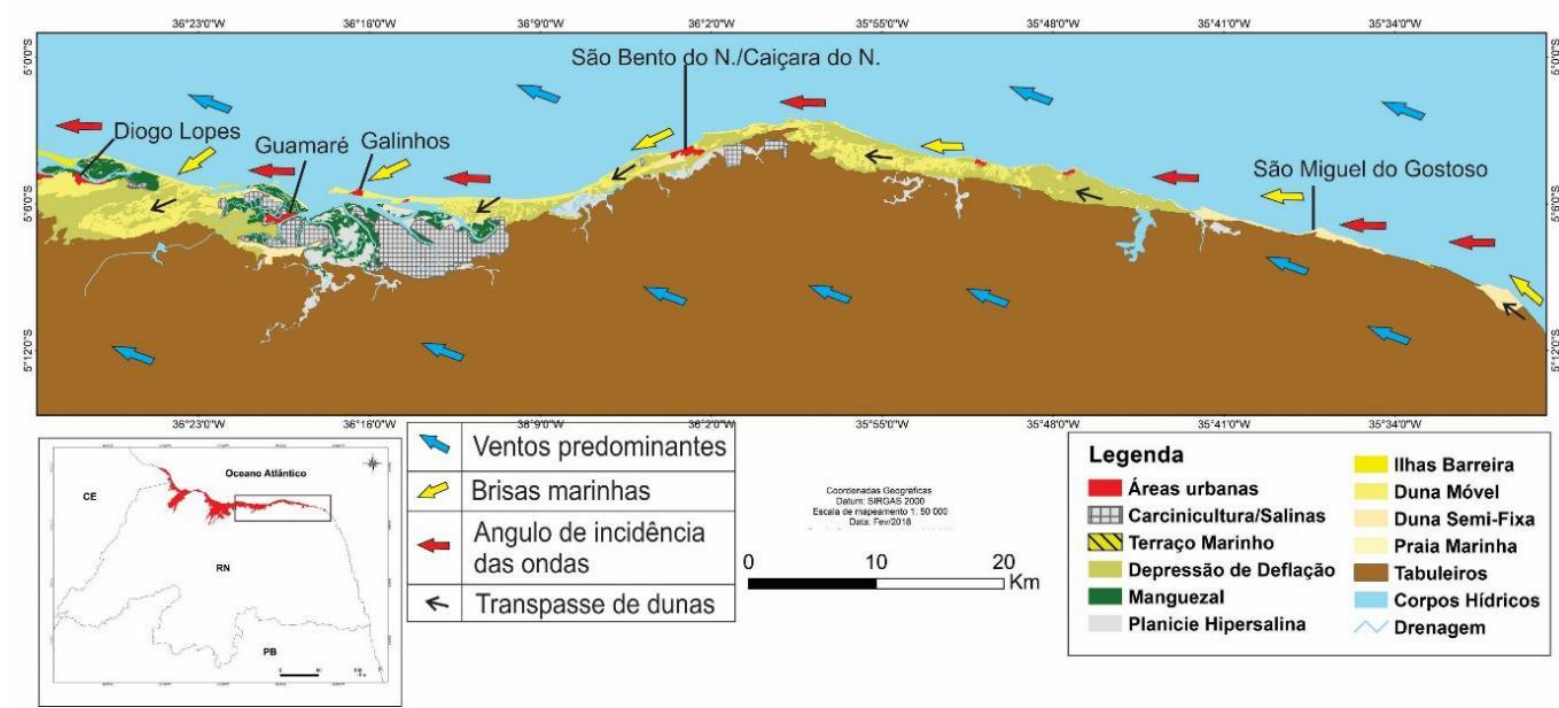

Figura 6: Direção resultante dos ventos, direção da deriva eólica, direção da brisa marítima (marinha) e direção da brisa terrestre na planície costeira dos subcompartimentos Deltas de Maré de Diogo Lopes e Galinhos/Guamaré e São Bento do Norte-Touros. Fonte dos dados INMET.

\section{Conclusões}

A Costa Branca ou Costa do Sal é um trecho bastante peculiar do litoral brasileiro. Suas particularidades residem em aspectos ambientais como vegetação, geomorfologia e clima, bem como em aspectos das 
atividades produtivas nela praticadas. $\mathrm{O}$ trecho intercala paisagens esbranquiçadas de salinas, planícies hipersalinas, dunas escavadas, manguezais e vegetação de caatinga, motivos pelos quais recebe sua denominação.

Foram mapeadas nove unidades de paisagem, além de ter se trabalhado com direção da deriva eólica, direção da brisa marítima (marinha) e direção da brisa terrestre, condicionados pelas interações atmosferaterra-oceano com constantes ventos, chuvas escassas e grande disponibilidade de areias marinhas que transformam suas paisagens de forma quase que instantânea na maior parte dos ambientes. A metodologia empregada no texto tem sido utilizada com êxito em trabalhos na escala taxonômica das geofácies, na qual a fisionomia é o critério definidor do mapeamento.

Diante do exposto, espera-se que o trabalho venha a contribuir para o ordenamento territorial e gerenciamento costeiro na área analisada a partir do mapeamento de unidades de paisagem e posterior análise sistêmica destas, assim como crie subsídios para mapeamentos de maior detalhe, uma vez que o sistema taxonômico utilizado para balizar e justificar o uso das geofácies como táxon escolhido é capaz de fomentar comparações com as demais paisagens da região Nordeste do Brasil.

\section{Agradecimentos}

Os autores agradecem ao Conselho Nacional de Desenvolvimento Científico e Tecnológico - CNPq pela bolsa de produtividade em pesquisa do primeiro autor e pelo financiamento da pesquisa por meio da Chamada CNPq/ MCTI No 25/2015 Ciências Humanas, Sociais e Sociais Aplicadas. Agradecem ainda à CAPES pela bolsa de mestrado do segundo autor. DFSC agradece ao Instituto Nacional de Áreas Úmidas INAU/INCT-CNPq (MCTI/CNPq/CAPES/FAPs - Proc.465436/2014-5/2017-2020) pelo apoio financeiro a esta pesquisa.

\section{Referências}

BERTRAND, G. Paisagem e Geografia Física global: esboço metodológico. Cruz, O. (trad.) Cadernos de Ciências da Terra. São Paulo: USP-IGEOG, n. 43, 1972.

BERTRAND, G.; BERTRAND, C. Uma Geografia transversal e de travessias: o meio ambiente através dos territórios e das temporalidades. Maringá: Massoni, 2007.

CEARÁ, 2006. Lei no 13.796, de 30 de junho de 2006 (DOE - 30.06.06).

COSTA, D. F. S. Análise fitoecológica do manguezal e ocupação das margens do estuário hipersalino Apodi/Mossoró (RN - Brasil). 2010. Dissertação (Mestrado) - Programa Regional de Pós-Graduação em Desenvolvimento e Meio Ambiente, Universidade Federal do Rio Grande do Norte, Natal, 2010.

COSTA, D. F. S. Caracterização ecológica e serviços ambientais prestados por salinas tropicais. 2013. 206f. Tese (Doutorado em Ecologia, Biodiversidade e Gestão de Ecossistemas) - Programa de Pós-graduação em Biologia, Departamento de Biologia, Universidade de Aveiro. Aveiro - Portugal, 2013.

COSTA, D. F. S. Serviços ecossistêmicos prestados pelos manguezais do Rio Grande do Norte (Nordeste do Brasil). Os desafios da geografia física na fronteira do conhecimento, Campinas, v. 1, n. 1, p 1127-1136, 2017.

COSTA, D. F. S. et al. Breve revisão sobre a evolução histórica da atividade salineira no estado do Rio Grande do Norte (Brasil). Sociedade \& Natureza, Uberlândia, v. 25, n. 1, p. 21-34, 2013.

COSTA, D. F. S. et al. Análise dos serviços ambientais prestados pelas salinas solares. Boletim Gaúcho de Geografia, Porto Alegre, v. 41, p. 206-220, 2014a.

COSTA, D. F. S. et al. Análise fitoecológica e zonação do manguezal em um estuário hipersalino. Mercator (Fortaleza. Online), v. 13, p. 119-126, 2014 b.

COSTA, D. F. S. et al. O sal de ontem e as salinas de hoje: análise da produção de sal marinho no Rio Grande do Norte. In: ALBANO, G.P.; ALVES, L.S.F.; ALVES, A.M. (Org.). Capítulos de Geografia do Rio Grande Norte. Natal: Imprensa Oficial do Rio Grande do Norte e CCHLA-UFRN, 2015, v. 2, p. 37-63. 
DINIZ, M. T. M. Condicionantes socioeconômicos e naturais para a produção de sal marinho no Brasil: as particularidades da principal região produtora. 2013. 227f. Tese

(Doutorado em Geografia). Programa de Pós-Graduação em Geografia, Universidade Estadual do Ceará, 2013.

DINIZ, M. T. M.; OLIVEIRA, A. V. P. Mapeamento das unidades de paisagem do estado do Rio Grande do Norte, Brasil. Boletim Goiano de Geografia, Goiânia, v. 38, n. 2, p. 342 - 364, 2018.

DINIZ, M. T. M.; OLIVEIRA, G. P. Proposta de compartimentação em mesoescala para o litoral do Nordeste Brasileiro. Revista Brasileira de Geomorfologia, Brasília, v. 17, p. 565-590, 2016.

DINIZ, M. T. M.; PEREIRA, V. H. C. Climatologia do estado do Rio Grande do Norte, Brasil: Sistemas atmosféricos atuantes e mapeamento de tipos de clima. Boletim Goiano de Geografia (Online), Goiânia, v. 35, p. 488-506, 2015.

DINIZ, M. T. M.; SILVA, S. D. R. O Método Indutivo e a pesquisa em Geografia: aplicação no mapeamento de unidades da Paisagem. Caderno de Geografia, Belo Horizonte, v. 28, n. 54, p. 731-745, 2018.

DINIZ, M. T. M.; VASCONCELOS, F. P. Aspectos históricos e dinâmica locacional da economia salineira brasileira. Boletim Gaúcho de Geografia, Porto Alegre, v. 43, p. 1-26, 2016.

DINIZ, M. T. M.; VASCONCELOS, F. P. Condicionantes naturais à produção de sal marinho no Brasil. Mercator (Fortaleza On-line), v. 16, p. 1-19, 2017.

DNPM. Departamento Nacional de Produção Mineral. Sumário Mineral. Brasília: DNPM/DIPLAM, 2015.

GUERRA, A. T. Dicionário Geológico-Geomorfológico. 8 ed. Rio de Janeiro: IBGE, 1993.

IBGE. INSTITUTO BRASILEIRO DE GEOGRAFIA E ESTATÍSTICA. Manual Técnico de Geomorfologia. Rio de Janeiro: IBGE, 2009. 175p.

IBGE. INSTITUTO BRASILEIRO DE GEOGRAFIA E ESTATÍSTICA. Manual Técnico da Vegetação Brasileira. Rio de Janeiro: IBGE, 2012.271p.

INMET. Instituto Nacional de Meteorologia. Normais Climatológicas do Brasil 1961-1990. Organizadores: Andrea Malheiros Ramos, Luiz André Rodrigues dos Santos, Lauro Tadeu Guimarães Fortes. Brasília, DF: INMET, 2009.

JUNK. W. J. et al. Brazilian wetlands: their definition, delineation, and classification for research, sustainable management, and protection. Aquatic Conserv: Ma. Freshw. Ecosyst., Chichester v. 24, n. 1, p. 05-22, 2014.

KOUSKY, V. E. Diurnall rainfall variation in the Northeast Brazil. Monthly Weather Review, Boston, v. 108, n. 4, p. $488-498.1980$.

LACERDA, L. D. The changing pressures on neotropical mangroves. ITTO Tropical Forest Update, Yokohama, v. 26, p. 8, 2017.

LOVELOCK, C. E. et al. Nutrient enrichment increases mortality of mangroves. PLoS ONE, San Francisco, v. 4, n. 5, e5600, 2009.

MAIA, R. P. Geomorfologia e neotectônica no vale do rio Apodi-Mossoró RN. Natal, 2012. 218f. Tese (Doutorado em Geodinâmica). Programa de Pós-Graduação em Geodinâmica e Geofísica, Universidade Federal do Rio Grande do Norte, Natal, 2012.

MEIRELES, A. J. A. Geomorfologia costeira: funções ambientais e sociais. 2. ed. Fortaleza: Edições UFC, 2014. 489p. 
MEIRELES, A. J. A.; RUBIO, R. P. Un abordaje sistémico - las terrazas marinas como geoelemento de integración entre los procesos morfogenéticos en llanuras costeras. In: VII Congresso da ABEQUA, 1999, Porto Seguro. VII Congresso da ABEQUA. Porto Seguro - BA, 1999. v. 1.

PANIZZA, A.; FONSECA, F. Técnicas de interpretação visual de imagens. GEOUSP - Espaço e Tempo (Online), São Paulo, v. 30, p. 30-43, 2011.

PELlegrini, J. A. C. Caracterização da Planície Hipersalina (apicum) associada a um bosque de mangue em Guaratiba, Baía de Sepetiba, Rio de Janeiro - RJ. 2000. Tese (Doutorado). Programa de PósGraduação em Oceanografia, Universidade de São Paulo, São Paulo, 2000.

SAYRE, R. et al. Natureza em foco: avaliação ecológica rápida. Arlington: The Nature Conservancy, 2003.

SCHAEFFER-NOVELli, Y.; COELHO JR., C.; TOGNELLA-DE-ROSA, M. Manguezais. São Paulo: Ática, 2004. 48 p.

SILVA, A. M. A et al. Zooplankton (Cladocera and Rotifera) variations along a horizontal salinity gradient and during two seasons (dry and rainy) in a tropical inverse estuary (Northeast Brazil). Pan-American Journal of Aquatic Sciences, Montevidéu: v. 4, n. 2, p. 226-238, 2009.

SOUZA, V. C.; LORENZI, H. Botânica Sistemática: guia ilustrado para identificação das famílias de angiospermas da flora brasileira, baseado em AGP II. Nova Odesa-SP: Instituto Plantarum, 2005. 640p.

SUGUIO, K. Geologia do quaternário e mudanças ambientais. São Paulo: Oficina de Textos, 2010.

TABOSA, W. F. T. Monitoramento Costeira das Praias de São Bento do Norte e Caiçara do Norte - RN. 2002. Dissertação (Mestrado). Programa de Pós-graduação em Geodinâmica e Geofísica, Universidade Federal do Rio Grande do Norte, Natal, 2002.

TOMLINSON, P. B. The botany of mangroves. Cambridge: Cambridge University Press, 1986. 413 p.

VITAL, H. Rio Grande do Norte. In: MUEHE, D. (Org.). Erosão e Progradação do Litoral Brasileiro. Rio de Janeiro: Ministério do Meio Ambiente (MMA), 2006, v. 1, p. 132- 154. 